\title{
Neuro-Fuzzy Model for the Prediction and Classification of the Fused Zone Levels of Imperfections in Ti6Al4V Alloy Butt Weld
}

\author{
Giuseppe Casalino, ${ }^{1}$ Sabina Luisa Campanelli, ${ }^{1}$ and Fabrizio Memola Capece Minutolo ${ }^{2}$ \\ ${ }^{1}$ Department of Mechanics, Mathematics and Management, Politecnico di Bari, Viale Japigia 182, 70126 Bari, Italy \\ ${ }^{2}$ Department of Materials and Production Engineering, University of Naples Federico II, Piazzale Tecchio 80, 80125 Naples, Italy \\ Correspondence should be addressed to Sabina Luisa Campanelli; campanel@poliba.it
}

Received 10 May 2013; Accepted 3 September 2013

Academic Editor: Martha Guerrero

Copyright (C) 2013 Giuseppe Casalino et al. This is an open access article distributed under the Creative Commons Attribution License, which permits unrestricted use, distribution, and reproduction in any medium, provided the original work is properly cited.

Weld imperfections are tolerable defects as stated from the international standard. Nevertheless they can produce a set of drawbacks like difficulty to assembly, reworking, limited fatigue life, and surface imperfections. In this paper Ti6Al4V titanium butt welds were produced by $\mathrm{CO}_{2}$ laser welding. The following tolerable defects were analysed: weld undercut, excess weld metal, excessive penetration, incomplete filled groove, root concavity, and lack of penetration. A neuro-fuzzy model for the prediction and classification of the defects in the fused zone was built up using the experimental data. Weld imperfections were connected to the welding parameters by feed forward neural networks. Then the imperfections were clustered using the C-means fuzzy clustering algorithm. The clusters were named after the ISO standard classification of the levels of imperfection for electron and laser beam welding of aluminium alloys and steels. Finally, a single-value metric was proposed for the assessment of the overall bead geometry quality. It combined an index for each defect and functioned according to the criterion "the-smallest-the-best."

\section{Introduction}

Titanium and its alloys are considered as one of the best engineering metals because of the combination of properties such as elevated strength-to-weight ratio, high fatigue life, toughness, excellent resistance to corrosion, and good fatigue properties. High-strength-to-weight ratio and superior corrosion resistance make titanium attractive for many chemical, marine, and military applications. The compatibility with carbon fibre composite makes titanium alloys also suitable for aeronautical applications. Ti6 Al4V is presently one of the most widely used titanium alloy, accounting for more than $50 \%$ of all titanium tonnage in the world, and to date no other titanium alloy has been a threat to its dominant position.

Titanium alloys may be joined by a wide variety of conventional and solid-state processes although their chemical reactivity requires special precautions to avoid contamination of the fusion and heat-affected zones both on the face and root sides. The fusion welding of titanium is performed principally in inert gas-shielded arc and high-energy beam welding processes.

Gas-shielded laser welds are produced with very interesting results concerning both the weld bead morphology and the mechanic properties. Both Helium and Argon shielding gases are commonly used, and Helium proved to be more performing with respect to Argon [1].

Unfortunately, welds are not perfect and defect-free. Weld undercut, excess weld metal, excessive penetration, incomplete filled groove, root concavity, and lack of penetration can alter the form of the bead. These kinds of defect can cause a set of drawbacks that require reworking and also limited fatigue life, difficulty to assembly, and consequences of failure.

In the last two decades laser welding has received increasing confidence from worldwide manufacturers. Deep penetration, flexibility, precision, narrow heat affected zones are among its most effective features. Laser beam welding can produce high quality titanium weld by controlling the welding parameters [2]. 
Statistical or evidence-based artificial intelligence (AI) use optimization techniques to obtain high software performance that are based on evidence present in experimental data. Over the years, these techniques have given various solutions to modelling and optimization problems [3-5]. Among the available applications it is worth to highlight some works in the field of titanium laser manufacturing such as a model for the evaluation of laser welding efficiency and quality [6] and the capability of confirming the statistical significance of some welding parameters and their interactions using both the ANOVA and Taguchi approaches [7]. In this way, artificial neural networks have well established themselves as an optimisation technique in laser welding investigations [8].

In the case of titanium alloys the neural networks have been used for modelling the correlations in the properties [9] and to link the welding parameters to the metallurgical, the mechanical, and the weld geometry $[10,11]$.

Fuzzy logic has been widely utilised in the classification of the weld defects using the nondestructive method. By this method, the defects were classified to the right quality level. Compared with the ordinary ones, this method has higher accuracy and better robustness [12].

In this paper a large number of welds of the Ti6Al4V titanium alloy were produced by $\mathrm{CO}_{2}$ laser and then cut, etched and observed using an optical microscope. Six imperfections of the fused zone were measured and analysed.

Artificial neural networks (ANN) were implemented to connect the weld defects to the laser parameters. A supervised back-propagation type neural network was used and applied to the experimental data. The optimal network topology was obtained by an iterative algorithm which allows to test a large number of networks with varying quantities of neurons in each layer and varying numbers of epochs before choosing the network with the minimum error rate. The prerequisite for successfully testing such a large number of networks lay in using the Levenberg-Marquardt algorithm. In a direct approach the weld imperfections were calculated for the process parameters, and in a reverse one the latter were calculated for the former.

Then the Bezdek fuzzy logic [13] was used to calculate the upper limits of three clusters each significant imperfection. The clusters were named stringent, intermediate, and moderate and included smallest, average, and largest defects, respectively. The nomenclature used is compliant with the ISO standard for steel and aluminium welds. Therefore it was possible to assign each measure to a cluster, which determines the quality score for that tolerable defect.

Some difficulties can arise for the evaluation of the defectiveness of the bead geometry when several imperfections are considered together [14]. Therefore, a single-value metric was calculated, and following the-smallest-the-best criterion it was possible to give a single score to the weld imperfection.

Figure 1 shows the flow charts for how to use the neurofuzzy model. When the process parameters are known it is possible to calculate and classify the weld tolerable imperfections and then the laser welding capability (flow chart a). On the other hand when the specifications for the levels of the weld imperfections are known it is possible to

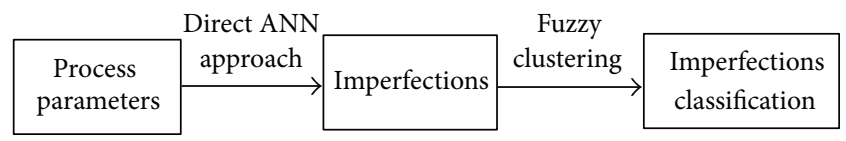

(a)

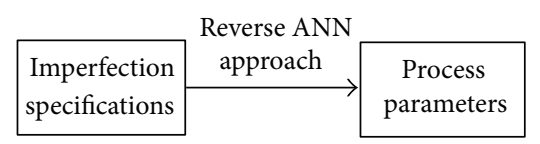

(b)

FIGURE 1: Flow charts for the application of the neuro-fuzzy model.

TABLE 1: Weld group and laser parameters.

\begin{tabular}{lcccc}
\hline $\begin{array}{l}\text { Group } \\
\text { no. }\end{array}$ & $\begin{array}{c}\text { Thickness } \\
(\mathrm{mm})\end{array}$ & $\begin{array}{c}\text { Laser power } \\
(\mathrm{W})\end{array}$ & $\begin{array}{c}\text { Welding } \\
\text { speed }(\mathrm{mm} / \mathrm{s})\end{array}$ & $\begin{array}{c}\text { Sample } \\
\text { size }\end{array}$ \\
\hline 1.0 & $2.61-2.62$ & $1500-2000$ & $25-120$ & 19 \\
1.1 & $2.81-2.89$ & $1500-2500$ & $35-140$ & 17 \\
1.2 & $2.54-2.61$ & $1500-2500$ & $50-120$ & 21 \\
1.3 & $1.36-1.39$ & $800-2000$ & $30-160$ & 21 \\
1.4 & $0.92-0.97$ & $600-1200$ & $40-140$ & 9 \\
\hline
\end{tabular}

calculate the process parameters that can generate those levels (flow chart b).

\section{Welding Conditions}

A mod. DC 025 Rofin Sinar $\mathrm{CO}_{2}$ laser was used operating in continuous wave regime to produce laser beam butt welds using Ti6A14V grade 5 annealed sheets whose thickness varied between 0.92 and $2.89 \mathrm{~mm}$.

The laser source characteristics were $2.5 \mathrm{~kW}$ max power level, slab type, and radio frequency. A polished copper, $200 \mathrm{~mm}$ focal length parabolic mirror was used as a laser beam focusing system. In order to move the work piece speeds ranged from 40 to $160 \mathrm{~mm} / \mathrm{s}$ using a $10 \mathrm{~mm} / \mathrm{s}$ step. Cleaning and polishing the parts to be joined avoided the porosity of the bead.

The pieces were lapped with $\mathrm{SiC}$ abrasive papers (grit numbers 600 and 800) followed by washing in ethyl alcohol. Chemical etching was performed with Keller's reagent: $2 \mathrm{~mL}$ $\mathrm{HF}+10 \mathrm{~mL} \mathrm{HNO}_{3}+88 \mathrm{~mL}$ deionized $\mathrm{H}_{2} \mathrm{O}$.

The morphological aspects of each weld were then numerically evaluated using a metallographic microscope, Nikon Eclipse, connected to a Nikon digital camera. To highlight the welding morphological characteristics, the crosssections of the beads were subjected to microscope observation measuring for each sample. Helium covering gases was used. Three cross-sections for each welding condition were considered to evaluate the bead imperfections.

Groups were set up for different weld thicknesses and welding conditions. Table 1 shows at a glance the process parameters and welds groups. 


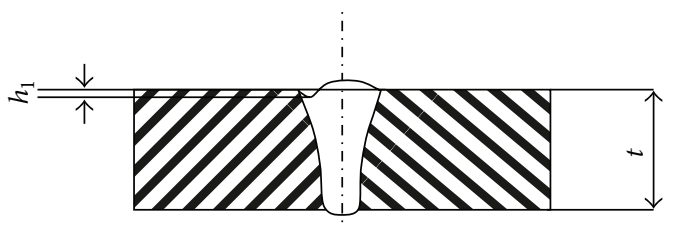

(a)

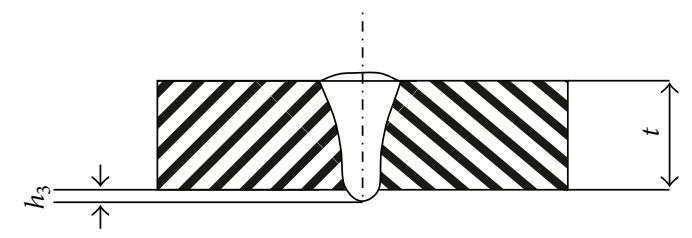

(c)

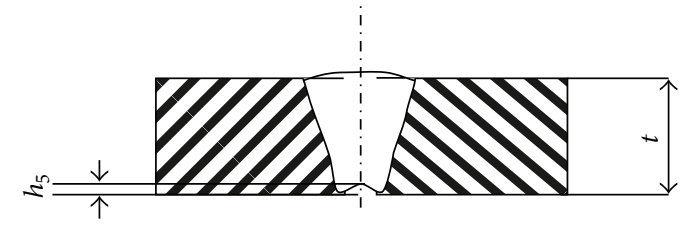

(e)

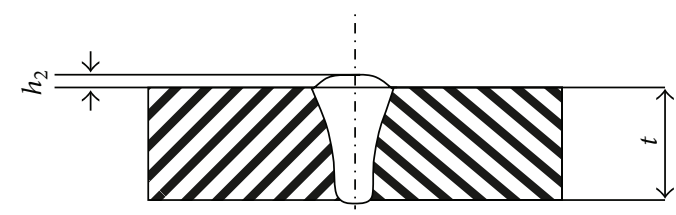

(b)

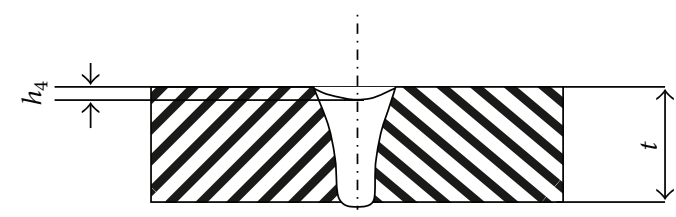

(d)

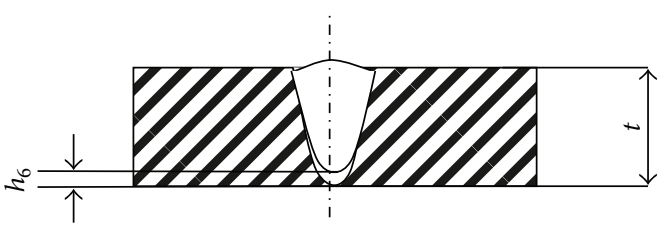

(f)

FIGURE 2: Geometrical imperfection considered for the analysis: (a) weld undercut $h_{1}$, (b) excess weld metal $h_{2}$, (c) excessive penetration $h_{3}$, (d) incomplete fill groove $h_{4}$, (e) root concavity $h_{5}$, and (f) lack of penetration $h_{6}$.

\section{Imperfection Evaluation}

3.1. Imperfection Description. The EN ISO 13919 guidance on the levels of tolerable defects (imperfections) in electron and laser beam welded joints in steel and Aluminium was used as a reference for the imperfections nomenclature $[15,16]$.

The three levels included in the ISO standard are defined in such a way to allow application to a wide range of welded fabrications. The levels refer to the production quality as opposed to the fitness for purpose of the product manufactured. The levels are moderate, intermediate, and stringent.

When significant deviations from the joint geometries and dimensions stated in the ISO standard are present in the welded product, it is necessary to evaluate to what extent the previsions of this standard can apply. Metallurgical and hardness aspects are not covered by this standard.

The imperfections analysed included weld undercut (Figure 2(a)), excess weld metal (Figure 2(b)), excessive penetration (Figure 2(c)), incomplete filled groove (Figure $2(\mathrm{~d})$ ), root concavity (Figure $2(\mathrm{e})$ ), and lack of penetration (Figure 2(f)).

3.2. Imperfection Analysis. The average values of each imperfection measure observed for the different groups are reported in Table 2. An imperfection was deemed significant if it was detected in more than $10 \%$ of the sample size. When an imperfection typology was absent or present in less than $10 \%$ of the sample size, the result was not reported in Table 2. The sample variability within each group was also calculated by either the standard deviation or the range, which is more suitable for sample size less than 10 (Table 3).
TABLE 2: Average values of the imperfections' performance measures $(\mathrm{mm})$.

\begin{tabular}{lcccccc}
\hline Group no. & $h_{1}$ & $h_{2}$ & $h_{3}$ & $h_{4}$ & $h_{5}$ & $h_{6}$ \\
\hline 1.0 & - & 0.136 & - & - & - & 0.910 \\
1.1 & - & 0.193 & 0.215 & - & - & 0.368 \\
1.2 & - & 0.160 & 0.133 & - & - & 0.320 \\
1.3 & 0.032 & 0.100 & 0.085 & - & - & 0.325 \\
1.4 & 0.016 & 0.085 & 0.016 & - & - & 0.197 \\
\hline
\end{tabular}

TABLE 3: Standard deviations of the levels for imperfections.

\begin{tabular}{lcccccc}
\hline Group no. & $h_{1}$ & $h_{2}$ & $h_{3}$ & $h_{4}$ & $h_{5}$ & $h_{6}$ \\
\hline 1.0 & - & 0.038 & - & - & - & 0.47 \\
1.1 & - & 0.035 & 0.069 & - & - & 0.203 \\
1.2 & - & 0.050 & 0.059 & - & - & 0.118 \\
1.3 & 0.025 & 0.010 & 0.069 & - & - & 0.215 \\
1.4 & $0.007^{*}$ & $0.023^{*}$ & 0.007 & - & - & $0.088^{*}$
\end{tabular}

${ }^{*}$ Range $(\mathrm{mm})$.

Most of the welds did not show incomplete filled grooves $\left(h_{4}\right)$ and root concavities $\left(h_{5}\right)$; as a consequence, these imperfections were neglected in the classification algorithm. Weld undercut $\left(h_{1}\right)$ was frequently revealed in the He-shielded thin plates in the butt configuration and overlap welds.

The average levels for the remaining imperfections grew proportionally to the thickness of the butt welds when Helium gas was used for shielding. Argon gas seemed to produce lower levels of imperfections. In fact, neither excess weld metal nor lack of penetration was observed. 
The average lack of penetration $\left(h_{6}\right)$ was up to $35 \%$ for Ar-shielded welds and up to $15 \%$ for $\mathrm{He}$-shielded ones.

The use of Argon seems to produce fewer imperfections, both in number and size, than the use of Helium. Higher power levels can improve penetration while keeping low the levels of other imperfections when Argon is used.

He-shielded overlap welds showed weld undercut $\left(h_{1}\right)$, excess weld metal $\left(h_{2}\right)$, and excessive penetration $\left(h_{3}\right)$. Thick overlap welds also showed lack of penetration $\left(h_{6}\right)$.

Standard deviations and ranges were high for butt welds and low for overlap welds.

Based on the welds' analysis, the levels of imperfection from groups 2.1 to 2.4 were used to build a fuzzy model with the aim to classify those imperfections.

\section{Neural Network Prediction Model}

The used neural network was the multilayer feed forward type (MFNN). This kind of network is frequently used due to the fact that it acts as a universal interpolator in a wide range of cases in which input variables are to be related to a set of output variables.

This network is a supervised learning type, in that the input/output relation can only be learned based on a set of training data and then validated by means of a second set of data, which is called validation set.

The typical architecture of an MFNN is shown in Figure 3. It includes an input layer $(x)$, one or more hidden layers, and an output layer.

The input value for each neuron is determined as the weighted average of the output values of the neurons in the previous layer (1), whereas the output value is based on a sigmoidal or hyperbolic tangent activation function (2)

$$
\begin{aligned}
\operatorname{net}_{i}^{l+1} & =\sum_{i}^{N} w_{i j} \cdot x_{i}, \\
\text { out }_{i}^{l+1} & =f\left(\text { net }_{i}^{l+1}\right) .
\end{aligned}
$$

The test data available from the macroanalysis was subdivided into two sets: the training set, which included 62 examples, and the test set, which included 25 examples.

In the direct approach the networks were characterised by a three neurons layer input (power rating, thickness, and speed), a hidden layer, and by one output value for each network, which was the single imperfection. Therefore, four independent networks were trained and validated.

In the reverse approach the networks were characterised by a three neurons layer input (weld's imperfections), a hidden layer, and by a single output, which was either the welding speed or laser power. Therefore, two independent networks were trained and validated.

In order to investigate the network response in more detail a regression analysis between the network response and the corresponding targets was performed after the training and the validation sessions.

The more the regression slope $(m)$ is next to one the better is the fit, which outputs exactly equal to targets. Moreover, the correlation coefficient $(R)$ between the outputs and targets

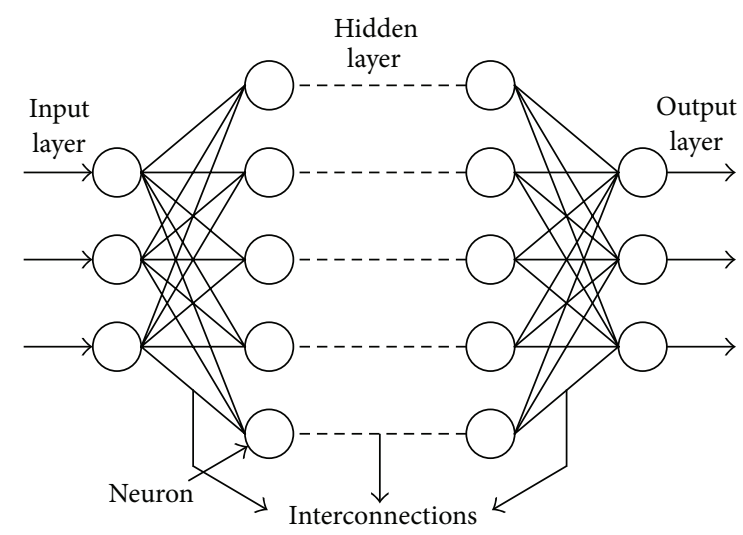

Figure 3: Network architecture.

was calculated. It is a measure of how well the variation in the output is explained by the targets. If this number is equal to 1 , then there is perfect correlation between targets and outputs.

Tables 4 and 5 report the better architecture and the performance data for the direct and the reverse approach, respectively. In this example we can see that the numbers of the regression slope and correlation coefficient are very close to 1 , which indicates a very good fit for the training and the validation sets.

\section{Fuzzy Model}

The fuzzy C-means clustering is a clustering algorithm for experimental data wherein a data point belongs to a cluster to a degree specified by a membership grade. It is an improvement over hard C-means clustering, and it provides a concise representation of a system's behaviour [17]. It uses an optimisation technique to solve the fuzzy classification task, and it is one of the most precise approaches to the classification problem. Recent results have shown that this grouping method performs much better than the neural network classification algorithm [18].

The fuzzy C-means algorithm is used to find a fuzzy partition so that the parameters under investigation can be classified into fuzzy subsets. Each partition of the data set into a subset can be described by a membership function.

The C-mean routine starts with an initial guess for the cluster centre, which is intended to mark the mean location of each cluster. By iteratively updating the cluster centres and the membership degrees for each data point, the calculation iteratively moves the cluster centres to the "right" location within the data set.

This iteration is based on minimizing an objective function that represents the distance from any given data point to a cluster centre weighted by that data point's membership degree. The fuzzy logic toolbox of Matlab can be used to perform the calculation [19].

In this application the data set consisted of the levels for imperfections $h_{1}, h_{2}, h_{3}, h_{6}$. For each kind of imperfection three centres were calculated. 
TABLE 4: Neural network architecture and performance for the direct approach.

\begin{tabular}{lcccccc}
\hline Imperfection & $\begin{array}{c}\text { Neurons in the } \\
\text { input layer }\end{array}$ & $\begin{array}{c}\text { Neurons in the } \\
\text { hidden layer }\end{array}$ & $\begin{array}{c}\text { Neurons in the } \\
\text { output layer }\end{array}$ & $\begin{array}{c}\text { Regression slope } \\
\text { for training }\end{array}$ & $\begin{array}{c}\text { Regression slope } \\
\text { for validation }\end{array}$ & $\begin{array}{c}\text { Correlation } \\
\text { coefficient }\end{array}$ \\
\hline$h_{1}$ & 3 & 6 & 1 & 0.994 & 0.962 & 0.912 \\
$h_{2}$ & 3 & 8 & 1 & 0.996 & 0.972 & 0.922 \\
$h_{3}$ & 3 & 9 & 1 & 0.989 & 0.976 & 0.938 \\
$h_{6}$ & 3 & 8 & 1 & 0.991 & 0.981 & 0.921 \\
\hline
\end{tabular}

TABLE 5: Neural network architecture and performance for the reverse approach.

\begin{tabular}{lcccccc}
\hline $\begin{array}{l}\text { Process } \\
\text { parameters }\end{array}$ & $\begin{array}{c}\text { Neurons in the } \\
\text { input layer }\end{array}$ & $\begin{array}{c}\text { Neurons in the } \\
\text { hidden layer }\end{array}$ & $\begin{array}{c}\text { Neurons in the } \\
\text { output layer }\end{array}$ & $\begin{array}{c}\text { Regression slope } \\
\text { for training }\end{array}$ & $\begin{array}{c}\text { Regression slope } \\
\text { for validation }\end{array}$ & $\begin{array}{c}\text { Correlation } \\
\text { coefficient }\end{array}$ \\
\hline Laser power & 3 & 11 & 1 & 0.976 & 0.942 & 0.907 \\
Welding speed & 3 & 14 & 1 & 0.986 & 0.952 & 0.904 \\
\hline
\end{tabular}

TABLE 6: Centres for imperfection clusters ( $\mathrm{mm})$.

\begin{tabular}{lccc}
\hline & Lower & Middle & Upper \\
\hline Undercut $\left(h_{1}\right)$ & 0.012 & 0.033 & 0.071 \\
Excess metal $\left(h_{2}\right)$ & 0.054 & 0.116 & 0.194 \\
Excessive penetration $\left(h_{3}\right)$ & 0.035 & 0.134 & 0.243 \\
Lack of penetration $\left(h_{6}\right)$ & 0.198 & 0.457 & 0.66 \\
\hline
\end{tabular}

TABLE 7: Limits for imperfections for quality levels (mm).

\begin{tabular}{lrcc}
\hline & Stringent & Intermediate & Moderate \\
\hline Undercut $\left(h_{1}\right)$ & $0 \div 0.012$ & $0.012 \div 0.033$ & $0.033 \div 0.071$ \\
Excess metal $\left(h_{2}\right)$ & $0 \div 0.054$ & $0.054 \div 0.116$ & $0.116 \div 0.194$ \\
Excessive penetration $\left(h_{3}\right)$ & $0 \div 0.035$ & $0.035 \div 0.134$ & $0.134 \div 0.243$ \\
Lack of penetration $\left(h_{6}\right)$ & $0 \div 0.198$ & $0.198 \div 0.457$ & $0.457 \div 0.66$ \\
\hline
\end{tabular}

The different categories were named "stringent," "intermediate," and "moderate" according to the EN ISO 13919 that assign to the "moderate" class the higher level of tolerable defects, to the "intermediate" the average level of imperfection, and to the "stringent" the lower one.

The calculated positions of the cluster centre are listed in Table 6. The "stringent" cluster has the minimum value for each kind of imperfection.

On the basis of the calculated centres it is possible to select the limits for imperfections for quality levels. Table 7 shows the limits that the authors calculated using the Matlab fuzzy logic toolbox.

The three sets of limits can be used for a selection that can be made for each particular application. Levels should be prescribed before the start of production, preferably at the inquiry or order stage. For special purposes, additional details may need to be prescribed.

\section{Single Score Metric}

The definition of three quality levels produced by the fuzzy logic application enabled a convenient classification of the level of imperfection for each given fused zone defect. Maintaining separated information about each quality feature ensures a higher detailed evaluation when some specification has to be either communicated among parties involved in the production or tested on the welds produced. However difficulties can arise when the welds have to be compared to each other since the minimisation of the different kinds of imperfection can conflict together. In this case the synthesis of quality information in a single metric represents a convenient solution.

With the aim of classifying the global quality level of a titanium alloy laser welded joint, a numerical index, named $R_{\text {tot }}$, was developed. It was a "the-smaller-the-better" type index, and it took into account the membership of an imperfection to one of the levels previously defined. It is defined as follows:

$$
R_{\mathrm{tot}}=\sqrt{\sum_{i=1}^{l} R_{i}^{2}},
$$

where $l$ is the number of imperfections considered and $R_{i}$ a standardized index relative to the $i$ th feature. This score was obtained using a piecewise linear model based on the cluster centre values. In each interval, the starting point coincided with the ending point of the previous interval, and the slope of the model curve was equal to the width of the interval. The starting point of the first interval was assumed equal to zero. Finally, the score obtained was standardized by dividing the absolute maximum of the curve, which was the value corresponding with the highest cluster centre. Let $c_{j}$ be the bounds of the quality intervals, with $j=0,1,2,3, x$ the quality measurement relative to the $i$ th feature, and $c_{0}=0$. Then $R_{i}$ was expressed as follows:

$$
R_{i}=\left\{\begin{array}{c}
\frac{\left(c_{1}-c_{0}\right)\left(x-c_{0}\right)}{\left(c_{1}-c_{0}\right)^{2}+\left(c_{2}-c_{1}\right)^{2}+\left(c_{3}-c_{2}\right)^{2}} \\
c_{0} \leq x \leq c_{1} \\
\frac{\left(c_{1}-c_{0}\right)^{2}+\left(c_{2}-c_{1}\right)\left(x-c_{1}\right)}{\left(c_{1}-c_{0}\right)^{2}+\left(c_{2}-c_{1}\right)^{2}+\left(c_{3}-c_{2}\right)^{2}} \\
c_{1}<x \leq c_{2} \\
\frac{\left(c_{1}-c_{0}\right)^{2}+\left(c_{2}-c_{1}\right)^{2}+\left(c_{3}-c_{2}\right)\left(x-c_{2}\right)}{\left(c_{1}-c_{0}\right)^{2}+\left(c_{2}-c_{1}\right)^{2}+\left(c_{3}-c_{2}\right)^{2}} \\
c_{2}<x \leq c_{3} .
\end{array}\right.
$$


TABLE 8: $R_{\text {tot }}$ values calculated for some samples.

\begin{tabular}{lccccccccc}
\hline Sample no. & $h_{1}$ & $h_{2}$ & $h_{3}$ & $h_{6}$ & $R_{1}$ & $R_{2}$ & $R_{3}$ & $R_{6}$ & - \\
\hline 8 & 0.0503 & 0.1972 & 0.0294 & 0 & - & $\mathrm{NC}$ & - & NC \\
10 & 0 & 0.1606 & 0.2114 & 0 & 0 & 0.7972 & 0.8496 & 0 & 1.1651 \\
33 & 0.0318 & 0.1481 & 0 & 0.474 & 0.2759 & 0.7213 & 0 & 0.744 & 1.0723 \\
40 & 0 & 0.0652 & 0 & 0.729 & - & - & - & NC & NC \\
52 & 0 & 0.1708 & 0 & 0 & 0 & 0.8591 & 0 & 0 & 0.85911 \\
59 & 0 & 0 & 0 & 0.2918 & 0 & 0 & 0 & 0.4305 & 0.43051 \\
72 & 0.0317 & 0.1051 & 0 & 0 & 0.2749 & 0.4737 & 0 & 0 & 0.54767 \\
74 & 0.0067 & 0.11 & 0.1732 & 0 & 0.0396 & 0.4974 & 0.6679 & 0 & 0.83365 \\
\hline
\end{tabular}

(NC: not classifiable).

This kind of model ensured a progressive increase in the metric as the magnitude of the related imperfection increases. Moreover, since the wider was the interval the higher was the slope, a higher penalization was given to the values belonging to the wider intervals that meant a more severe distinction was possible between values belonging to the presumably most populated intervals.

Relatively to the analysis conducted in this paper, four features from the initial six ones were considered in the $R_{\text {tot }}$ evaluation since incomplete fill groove and root concavity proved not to be significant imperfections. The fact that the lack of penetration was opposed to the excessive penetration did not create any issue in the $R_{\text {tot }}$ calculation since the contribution of a lacking imperfection was null. For these reasons it was possible to consider $l$ equal to 3 . As from its definition, the $R_{\text {tot }}$ index varied in a finite interval $([0 ; \sqrt{3}])$ and presented two critical values which are 1 and $\sqrt{2} . R_{\text {tot }}$ values higher than 1 indicated the presence of at least two imperfections, values higher than $\sqrt{2}$ revealed the presence of three of imperfections.

It should be noted that it was not possible to apply the $R_{\text {tot }}$ index when an imperfection measurement exceeded the lowest quality limit for that imperfection, which was the largest centre value determined by the fuzzy logic. In these cases, the overall quality of the joint can be considered not satisfactory, which is indicated as not classifiable (NC). Table 8 shows the values of $R$ calculated for some welds.

\section{Conclusion}

In this paper a model for the prediction and the evaluation of the levels for imperfections for the fused zone of Ti6Al4V titanium alloy laser butt weld was proposed. It was based on multiple neural network mapping followed by a fuzzy logic clustering of the process parameters, and the tolerable levels for the weld imperfections. The calculation of a single score for the quality comparison between the welds was presented. It followed the-smaller-the-better criterion.

Both the prediction and the classification of the imperfections were based on a structured and objective model, which was built straight from experimental data.
The neural network connections were built both in the direct and inverse approaches.

The calculation of three quality clusters enabled a convenient classification and evaluation of each tolerable defect. When the quality of the beads was to be compared to each other the single metric evaluation criterion proved a better solution.

The use of this neuro-fuzzy method gives the opportunity to predict the quality of the fused zone which can make the titanium welding more suitable for the severe standard of the aeronautical and modern automotive industries for the weld imperfections.

\section{References}

[1] F. Caiazzo, F. Curcio, G. Daurelio, and F. M. C. Minutolo, "Ti6Al4V sheets lap and butt joints carried out by $\mathrm{CO}_{2}$ laser: mechanical and morphological characterization," Journal of Materials Processing Technology, vol. 149, no. 1-3, pp. 546-552, 2004.

[2] A. Squillace, U. Prisco, S. Ciliberto, and A. Astarita, "Effect of welding parameters on morphology and mechanical properties of Ti-6Al-4V laser beam welded butt joints," Journal of Materials Processing Technology, vol. 212, no. 2, pp. 427-436, 2012.

[3] A. G. Olabi, G. Casalino, K. Y. Benyounis, and A. Rotondo, "Minimisation of the residual stress in the heat affected zone by means of numerical methods," Materials and Design, vol. 28, no. 8, pp. 2295-2302, 2007.

[4] A. G. Olabi, G. Casalino, K. Y. Benyounis, and M. S. J. Hashmi, "An ANN and Taguchi algorithms integrated approach to the optimization of $\mathrm{CO}_{2}$ laser welding," Advances in Engineering Software, vol. 37, no. 10, pp. 643-648, 2006.

[5] S. L. Campanelli, G. Casalino, A. D. Ludovico, and C. Bonserio, "An artificial neural network approach for the control of the laser milling process," International Journal of Advanced Manufacturing Technology, vol. 66, no. 9-12, pp. 1777-1784, 2013.

[6] G. Casalino and F. M. C. Minutolo, "A model for evaluation of laser welding efficiency and quality using an artificial neural network and fuzzy logic," Proceedings of the Institution of Mechanical Engineers B, vol. 218, no. 6, pp. 641-646, 2004.

[7] G. Casalino, F. Curcio, and F. M. C. Minutolo, "Investigation on Ti6Al4V laser welding using statistical and Taguchi 
approaches," Journal of Materials Processing Technology, vol. 167, no. 2-3, pp. 422-428, 2005.

[8] K. Y. Benyounis and A. G. Olabi, "Optimization of different welding processes using statistical and numerical approachesa reference guide," Advances in Engineering Software, vol. 39, no. 6, pp. 483-496, 2008.

[9] S. Malinov and W. Sha, "Application of artificial neural networks for modelling correlations in titanium alloys," Materials Science and Engineering A, vol. 365, no. 1-2, pp. 202-211, 2004.

[10] Y. Wei, H. K. D. H. Bhadeshia, and T. Sourmail, "Mechanical property prediction of commercially pure titanium welds with artificial neural network," Journal of Materials Science and Technology, vol. 21, no. 3, pp. 403-407, 2005.

[11] A. Khorram, M. R. Soleymani Yazdi, M. Ghoreishi, and M. Moradi, "Using ANN approach to investigate the weld geometry of Ti $6 \mathrm{Al} 4 \mathrm{~V}$ titanium alloy," International Journal of Engineering and Technology, vol. 2, no. 5, pp. 491-498, 2010.

[12] L. Tao, T. J. Sun, and Z. H. Li, "Rough set based intelligent welding quality classification," World Academy of Science, Engineering and Technology, vol. 60, pp. 211-214, 2011.

[13] J. C. Bezdek, Pattern Recognition with Fuzzy Objective Function Algorithms, Plenum Press, New York, NY, USA, 1981.

[14] P. Sathiya and M. Y. Abdul Jaleel, "Grey-based Taguchi method for optimization of bead geometry in lase bead-on-plate welding," Advances in Production Engineering \& Management, vol. 5, no. 4, pp. 225-234, 2010.

[15] EN ISO 13919-1 Electrons and laser beam welded joints, Guidance on the levels for imperfections, part 1: steel, 1996.

[16] EN ISO 13919-2 Electrons and laser beam welded joints, Guidance on the levels for imperfections, Part 2: aluminum and its weldable alloys, 2001.

[17] H. J. Zimmermann, Fuzzy Set Theory and Its Application, Kluwer Academic, London, UK, 1991.

[18] Y. S. Tarng, H. L. Tsai, and S. S. Yeh, "Modeling, optimization and classification of weld quality in tungsten inert gas welding," International Journal of Machine Tools and Manufacture, vol. 39, no. 9, pp. 1427-1438, 1999.

[19] MATLAB Fuzzy Logic Toolbox the MathWorks Inc, Prentice Hall, Englewood Cliffs, NJ, USA, 1998. 

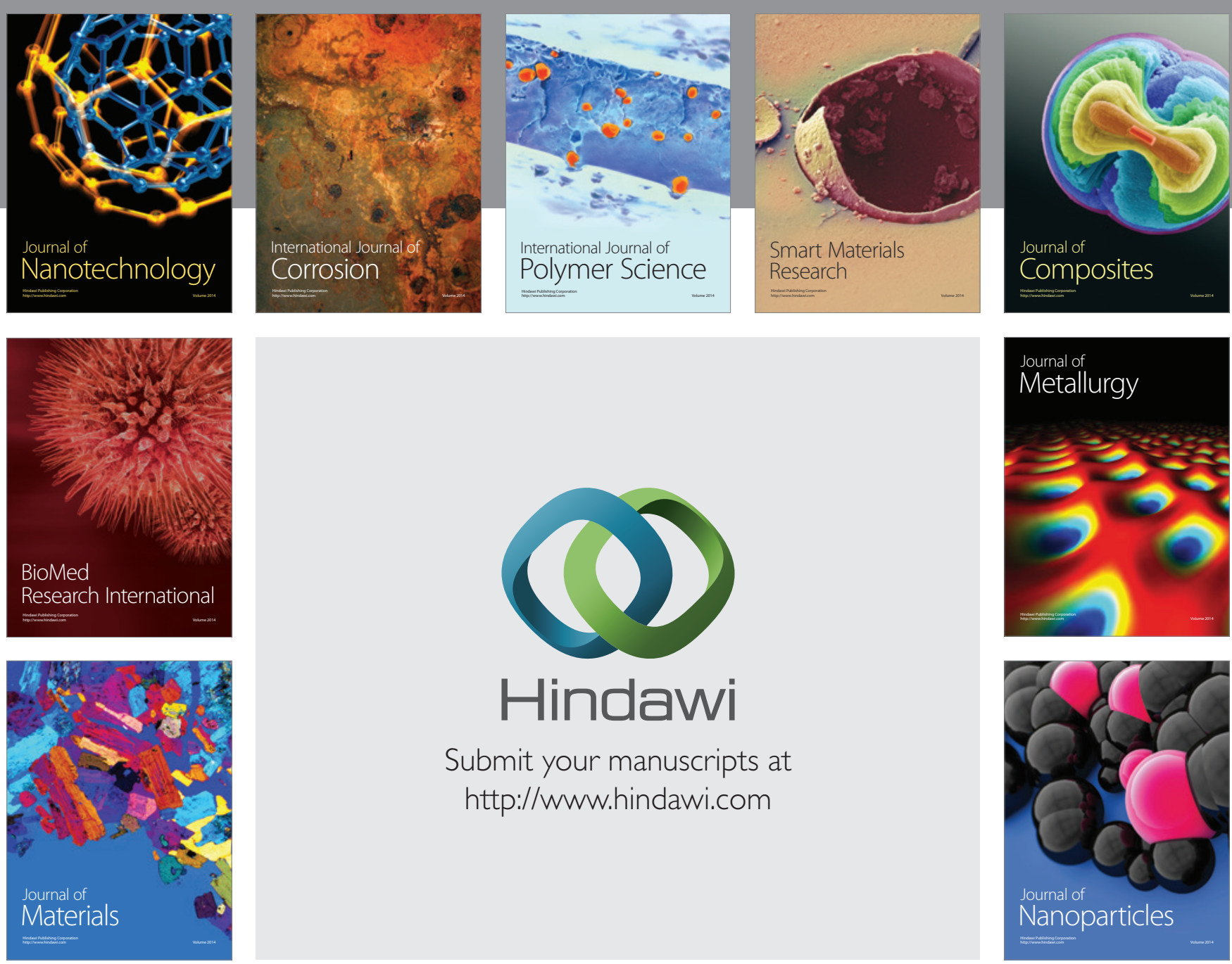

Submit your manuscripts at http://www.hindawi.com
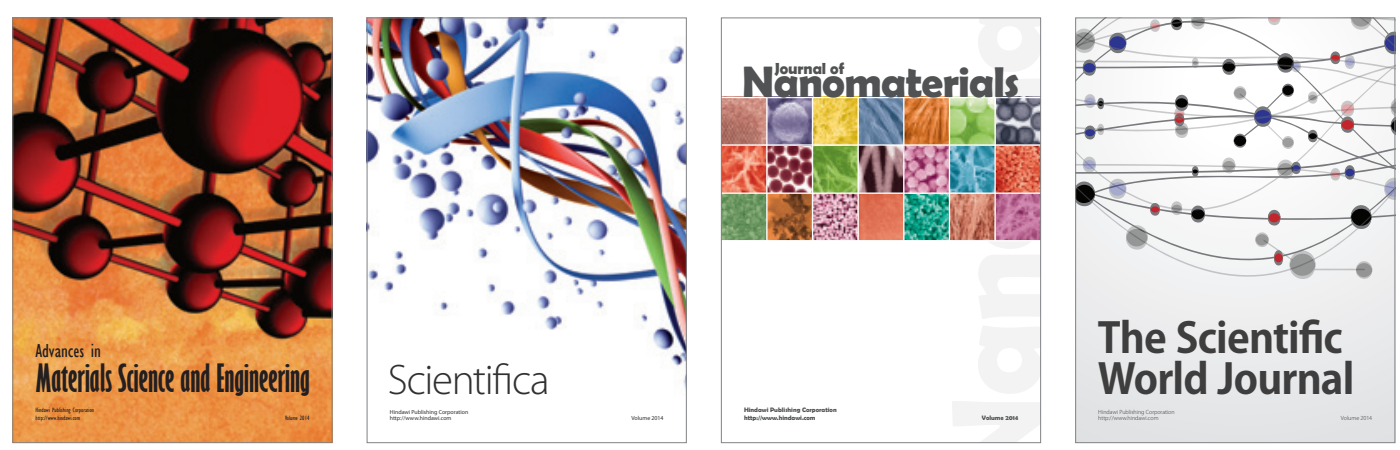

\section{The Scientific World Journal}
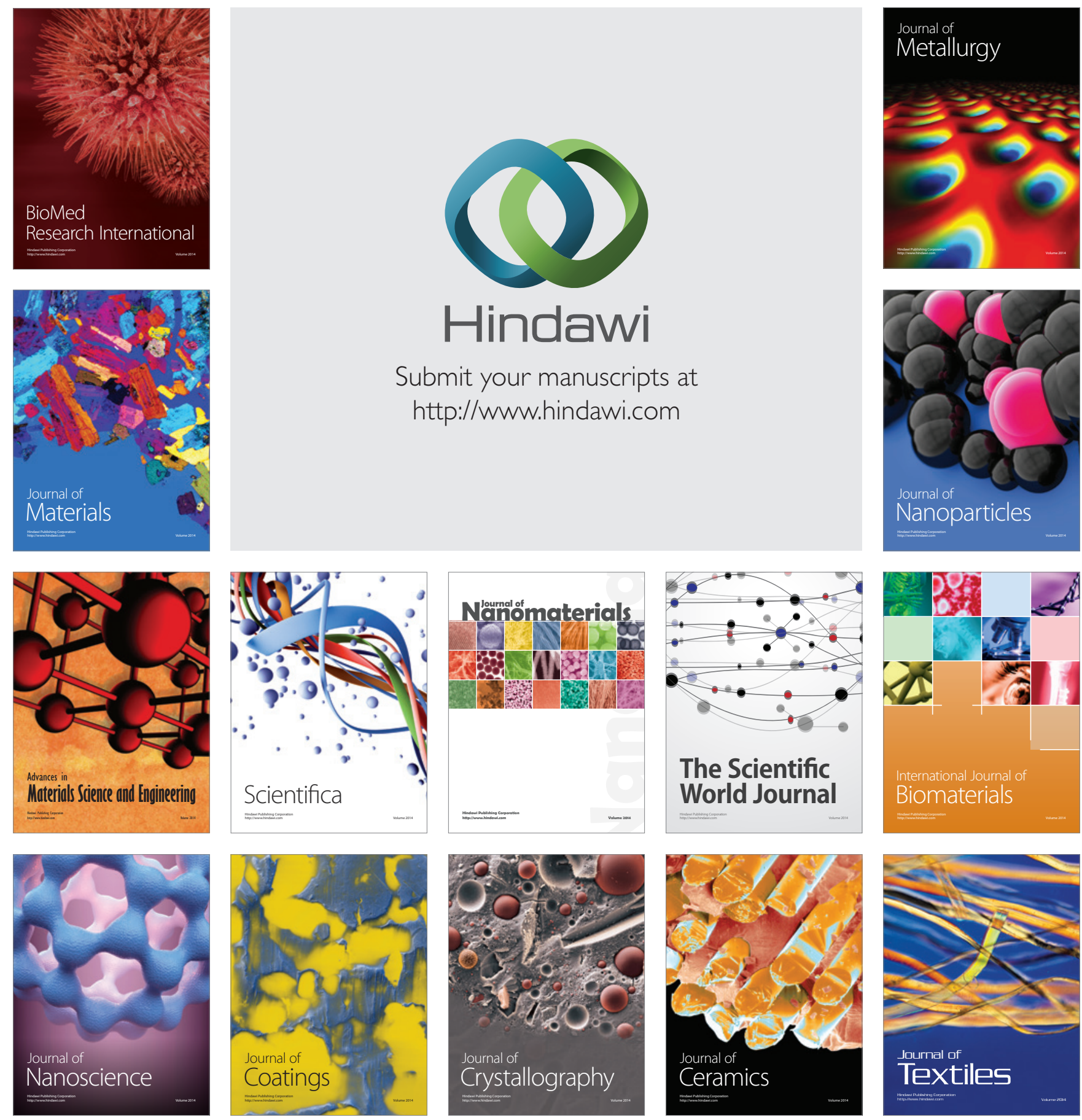